\title{
La restauración de la Cámara Santa (2012-2014): crónica de unas obras singulares
}

Jorge Hevia Blanco

Arquitecto

RESUMEN:

En la crónica de las obras realizadas en la Cámara Santa entre noviembre del 2013 y abril del 2014, se narra cómo se ha intervenido tanto en el exterior y en las zonas colindantes, como en el interior, incluyendo el reacondicionamiento expositivo.

ABSTRACT:

In the chronicle of the works made in the Cámara Santa between November 2013 and April 2014, it's related how was made the intervention both outside and in the surrounding areas, and inside, including the exhibition overhaul.

PALABRAS CLAVE:

Cámara Santa, restauración, prerrománico, catedral, Oviedo. 
La última intervención integral llevada a cabo en la Cámara Santa fue la necesaria para reparar los profundos daños ocasionados por su voladura, con dinamita, durante la Revolución de Octubre de 1934. Tras el devastador desastre fueron interviniendo diversos profesionales, como arquitectos (Alejandro Ferrant en época republicana y Luis Menéndez Pidal más tarde); arqueólogos (Manuel Gómez-Moreno primero y José Fernández Buelta después - éste con lápida y efigie pétrea, conmemorando su labor, colocada en el Cementerio de los Peregrinos en 1989) y escultores (Víctor Hevia Granda - con lápida y efigie de bronce, obra de Gerardo Zaragoza, dispuesta en la Torre de San Miguel en 1963). Todos ellos fueron aunando sus disciplinas y esfuerzos, escalonadamente, para conseguir lo que parecía imposible a la vista de la magnitud de los destrozos: su total reconstrucción con la completa recuperación del tesoro y las reliquias. Una pequeña placa de bronce en la clave de la bóveda del Camarín, que ya es historia, da fe del proceso de reparación: “El Excmo Señor D. Francisco Franco Bahamonde JEFE DEL ESTADO cerró esta bóveda el día 17 de septiembre de 1939".

Han transcurrido ochenta años desde aquella catástrofe y, tras su posterior reconstrucción, concluida en 1942, la Cámara Santa ha ido envejeciendo paulatinamente, detectándose en la actualidad numerosos achaques y carencias. Por este motivo la Consejería de Educación, Cultura y Deporte del Gobierno del Principado de Asturias puso en marcha un nuevo proyecto de actuación integral en tan singular enclave, en dos fases, al amparo del Plan Director de la Catedral de Oviedo y por tratarse de un bien, de origen altomedieval, declarado Patrimonio Cultural de la Humanidad, por la UNESCO, en 1998, (los proyectos de ambas fases fueron aprobados por el Consejo de Patrimonio Cultural de Asturias y por la Comisión Diocesana de Patrimonio Cultural de la Iglesia).

A mediados del año 2012 se restauró la envolvente exterior de la Cámara Santa (la primera fase): sustituyendo y retrazando las cubiertas, limpiando y tratando las fábricas pétreas de mampostería y sillería, sustituyendo el sistema de evacuación de aguas pluviales y rebajando los peldaños exteriores en contacto con su testero (con seguimiento arqueológico de Sergio Ríos González y por estar más altos que el inte- rior) para evitar, así, la entrada directa de agua a la cripta de Santa Leocadia.

Se trataba de reducir la humedad en la base de los muros, y de lograr la estanqueidad en fachadas y cubiertas, antes de intervenir en su interior (la zona más sensible del conjunto catedralicio, tanto por su contenedor como por sus emblemáticos contenidos).

También se actuó en las portadas góticas del itinerario de acceso (las incrustadas en la Torre Vieja y la Torre de San Miguel), en la Cripta de Santa Leocadia, y en la Antecámara (la parte alta de la Torre de San Miguel que alberga la puerta del acceso altomedieval a la Cámara Santa que fue destapiada), con trabajos diversos de restauración y la renovación de las instalaciones de iluminación. Por esas mismas fechas, y con financiación del Ministerio de Cultura, se llevó a cabo, en paralelo, una actuación restauradora en la contigua Capilla de Covadonga que incluyó la retirada del retablo neobarroco que ocultaba la zona de contacto entre la torre de San Miguel y la Cámara Santa, lo que colaboró a una mejor percepción del adosamiento entre las dos construcciones prerrománicas, tras disponer un nuevo mobiliario litúrgico exento. La liberación del testero puso también al descubierto los restos del guarnecido exterior que protegió la fábrica de la Cámara Santa, en su día, y la posible ménsula - repicada - que serviría de apoyo a una escalera de acceso, de madera.

Tras estos trabajos periféricos se llevaron a cabo unos estudios complementarios a petición del Instituto de Patrimonio Histórico Español - por un equipo pluridisciplinar de restauradores (Luis Suárez Saro y Pablo Klett Fernández), petrólogos (Araceli Rojo, Luis Valdeón y Félix Mateos) y arquitectos - con el objeto de precisar los métodos y tratamientos, con sus protocolos, que debían aplicarse a todas las superficies existentes del interior (pavimentos, paramentos, bóvedas y elementos pétreos y metálicos), durante la segunda fase de las obras, aunque también se incluyeron otros aspectos sobre la materialidad, condiciones medioambientales, técnicas de labra, pátinas y policromías, sales y humedades, patologías, iconografías y la evolución histórica de la disposición interior que tuvieron los contenidos. En estos protocolos se determinaron parámetros de aplicación tales como longitud de onda, energía del impulso, fluencia, potencia y energía (para el sistema lá- 


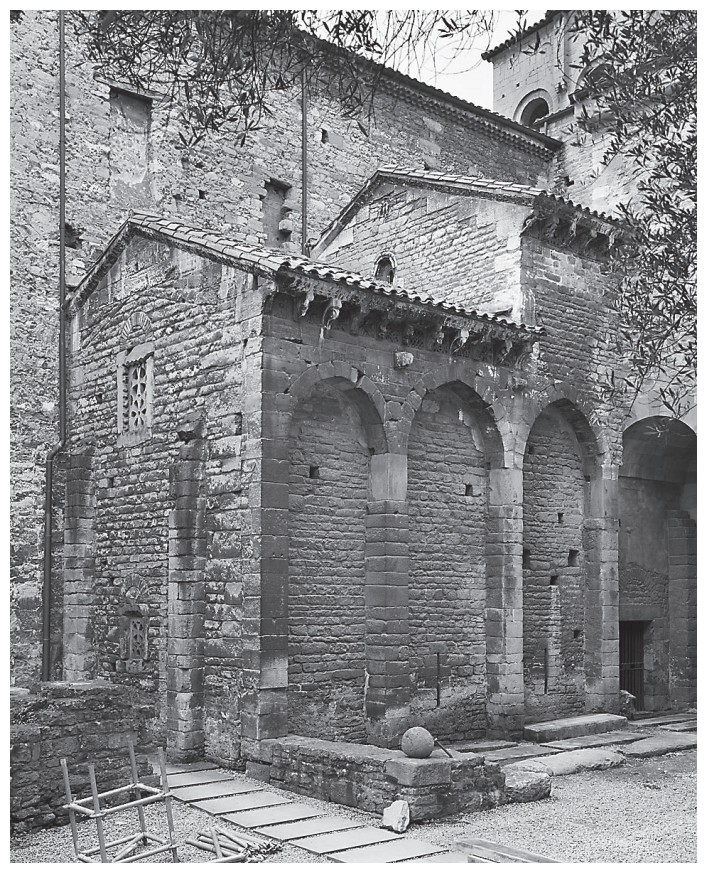

FIGURA 1. Aspecto exterior antes de la intervención. Roberto Tolín.

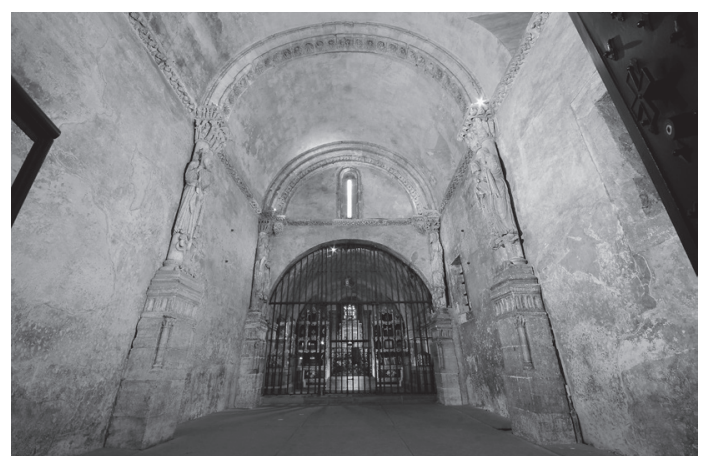

FIGURA 3. Aspecto interior antes de la intervención. Pablo Klett.

ser de limpieza), y presión de boquilla, distancia y ángulo de aplicación (en el sistema mecánico de microproyección). Incluso se hizo una exposición sobre los "Estudios complementarios de la Cámara Santa” en el Centro del Prerrománico Asturiano del Naranco, durante los últimos meses del 2013, auspiciada por la Dirección General de Patrimonio Cultural. En este documento agradecíamos la generosa aportación de las fotografías históricas facilitadas por D. Alfonso Suárez Saro (Archivo Luis Menéndez Pidal / Parte), la Hermandad de Defensores de Oviedo y el Museo de Bellas Artes de Asturias - en este caso un dibujo - aunque también contamos con dos importantes registros fotográficos, el de 1918, del Instituto Amatller de Arte Hispánico (Archivo MAS) - antes de la voladura de 1934 - y el de 1941, de los Fondos

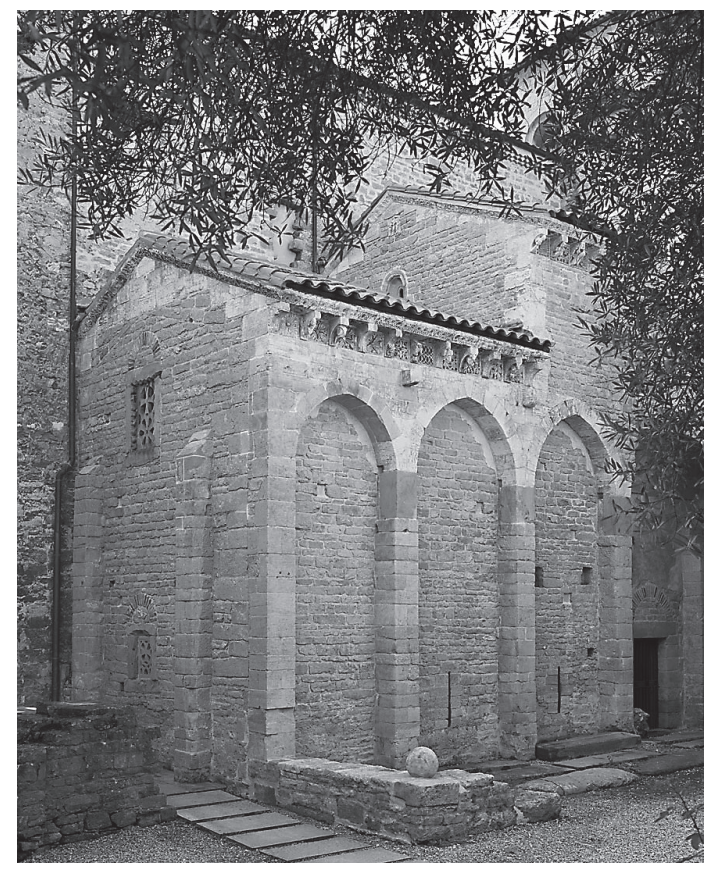

FIGURA 2. Aspecto exterior tras la intervención. Roberto Tolín

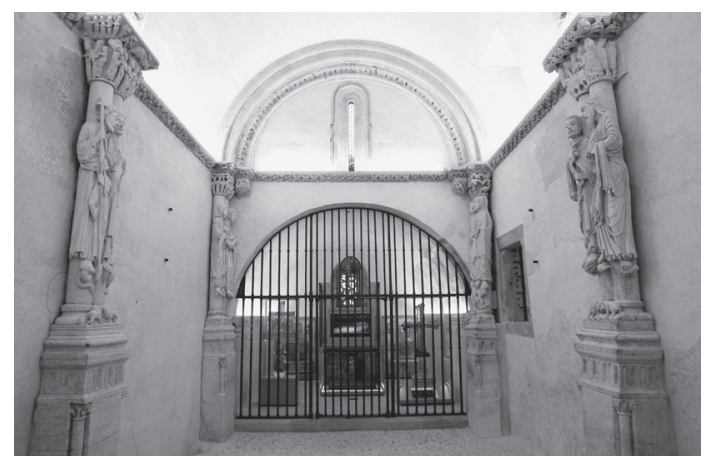

FIGURA 4. Aspecto interior tras la intervención. Alex Piña.

de la Catedral de Oviedo (Archivo Pedro Díaz Gómez), realizado en los últimos meses de la reconstrucción de la Cámara Santa.

La segunda fase, que corresponde a la vigésimosegunda intervención amparada por el Plan Director, dio comienzo el 25 de noviembre de 2013, dedicándose todo ese día al desalojo de las cruces, las arquetas y las reliquias, según el plan establecido por el Cabildo, y tras su documentación se fueron trasladando a lugares seguros o a cámaras de seguridad, levantándose acta de todo el proceso por el canónigo D. Agustín Hevia Ballina y valorándose las distintas piezas, previamente, por el equipo científico que ya había colaborado en la redacción del Catálogo del Museo de la Iglesia en el año 2009 (César García de Castro Valdés, Javier González 
Santos, Yayoi Kawamura Kawamura y Vidal de la Madrid Álvarez). Posteriormente se fue completando el acta con los resultados de un minucioso estudio de las reliquias que fueron realizando especialistas, investigadores, forenses y traumatólogos, depositándose el inventario actualizado de las reliquias, finalmente, en el interior de la arqueta de plata de Talleres Granda el sábado 12 de abril de 2014. El calendario de obra intentó ajustarse a los meses del invierno, coincidiendo con la menor afluencia de visitantes, a fin de minimizar las molestias que se iban a ocasionar al tratarse de uno de los focos de visita de mayor atracción de Asturias.

El aspecto interior que la Cámara Santa ofrecía al visitante, antes de las obras, se caracterizaba por la masiva presencia de las costras de ennegrecimiento acumuladas durante más de setenta años. Estas manchas, que invadían todas las superficies, también cubrían y camuflaban los resaltes y hendiduras que conformaban y delimitaban los volúmenes de la elaborada labra escultórica medieval, velando sus formas, pátinas, y texturas.

Para la eliminación de estas costras (provocadas por la oxidación de la capa protectora de cera que aglutinaba la suciedad de decenios y que ya estaba muy degradada), se utilizaron diversas tecnologías inocuas, previamente contrastadas, en función de unos parámetros concretos de aplicación fijados previamente por los petrólogos: disolvente neutro (white spirit) aplicado con hisopo, previo reblandecimiento de la cera superficial con pistola de aire caliente, sobre las piezas marmóreas de la arquitectura prerrománica; proyección con aire seco de micropartículas de piedra pómez sobre los guarnecidos y las superficies pétreas más neutras, y rayo láser sobre las escultóricas (tal y como ya habíamos hecho en los capiteles del claustro en el año 2003 con Rosa Esbert -impulsora de las nuevas tecnologías para el tratamiento de la piedra monumental- y que en esta ocasión, por su fallecimiento, no ha podido ayudarnos, si bien lo han hecho sus discípulos).

Posteriormente, se rebajaron los disgregados rellenos tras los pedestales, para perfilar sus sillares de dolomía de Laspra, se fueron completando los patinados perdidos, y se realizó el tratamiento conservativo final por el exterior, hidrorrepelente, mediante la aplicación de nanopartículas de óxidos cerámicos alojadas en un vehículo líquido a base de acetonas vo- látiles. Se trata de una técnica que permite la transpirabilidad del material pétreo sin modificar su aspecto, al no alterar su brillo y textura, y por no variar su tono y color. Este conjunto de actuaciones preservó toda la información subyacente, tanto los grafittis históricos de los peregrinos como los restos de las policromías detectadas. (Coincidiendo con las obras se llevó a cabo un completo registro gráfico sobre las marcas de cantero, inscripciones y grafittis, en el conjunto de la catedral, por el canónigo D. José María Hevia Álvarez y el fotógrafo Carlos de Posada, con más de mil fotografías).

Y como siempre, el proceso de limpieza resaltó y puso de manifiesto las faltas y roturas del material pétreo - en nuestro caso en las impostas y los arcos fajones - que antes, debido al ennegrecimiento, pasaban más desapercibidas. La respuesta fue restañar las principales heridas con mortero de restauración (allí donde el ojo se detenía) y dejar el resto sin reintegrar, como pequeños vestigios de los sucesos de 1934 . Y debido a la meticulosa limpieza salió a la luz una pequeña cruz de consagración grabada en la base de San Felipe, con el fondo tintado en color sanguina.

A modo de anécdota, técnica, debemos indicar la elección de la catedral de Oviedo para un proyecto de investigación europeo a tres años (noviembre 2011 - octubre 2014), en el que también participa la catedral de Colonia, a fin de comprobar la eficacia de los nuevos productos consolidantes, nanoparticulados, aplicados sobre superficies históricas de vidrio, piedra y madera. En su momento, a través de los discípulos de Rosa Esbert, sabremos tanto los resultados como si es posible su aplicación, conservativa, al Prerrománico Asturiano.

Tras la restauración realizada se ha recuperado una nueva percepción del conjunto, más gratificante a los ojos del observador, al retirarse el oscuro velo que cubría todas las superficies impidiendo su contemplación, salvo cinco pequeños testigos ubicados en sitios discretos, como referencia del estado inicial. Capiteles y cimacios, con sus múltiples escenas y decoraciones, los seis fustes pareados, con su apostolado, pedestales, arcos fajones con su decoración vegetal, líneas de imposta y las tres cabezas del Calvario ... todo ese rico y complejo ornamento románico, cubierto de una pátina medieval marfileña (constituida por blanco 


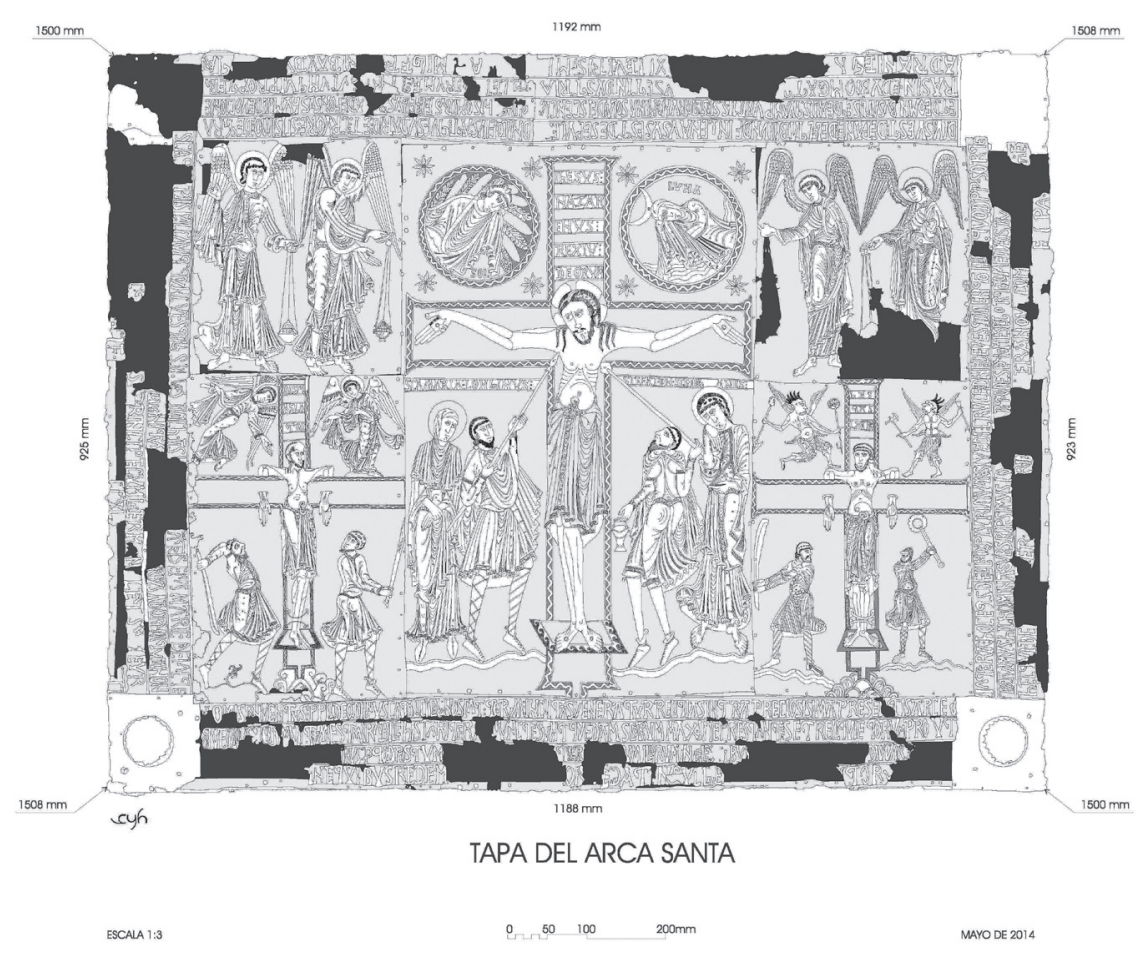

FIGURA 5. Dibujo de la tapa del Arca Santa. Cuenca y Hevia.

de plomo-albayalde-y blanco de huesos) para asemejarlo a un monumental trabajo de eboraria, antes semioculto, puede ahora apreciarse gracias a la legibilidad escultórica recuperada, en la que el más leve pliegue de un ropaje, la más fina arruga de una piel, o el más delicado rizo de una barba o un cabello, ya vuelven a percibirse con total nitidez. Y también algunos de los apóstoles recobraron la vista, tras reponer iris y pupilas en los ojos donde faltaban (el incrédulo Santo Tomás aún conservaba sus zafiros azules originales, y los que aún veían mantenían sus estucos negros de azabache).

De igual manera los elementos marmóreos altomedievales - basas, pilastras, fustes y capiteles - también han recuperado su protagonismo, al poder distinguirse sus verdosos veteados (una pictórica imitación del veteado marmóreo aún se conserva en un lateral del pedestal que soporta a San Andrés y San Mateo). Esta veteada y marmórea imitación, de pintura al óleo, llegó a cubrir toda la estatuaria románica y así fue vista en el siglo XVI (1572) por Ambrosio de Morales durante su viaje al Principado de Asturias por orden del rey Felipe II: ... "los pilares sobre que se sustenta la bóveda son ri- cos mármoles en que están entallados los doce Apóstoles, de dos en dos". (La pintura fue eliminada por Víctor Hevia en 1922, a iniciativa del Cabildo, poniéndose al descubierto el tono "pajizo" de la pátina).

Todas las superficies fueron tratadas. Ni un centímetro cuadrado quedó sin restaurar, por lo que también se incidió en suelos, paredes, bóvedas y los elementos metálicos que constituyen verjas, rejas y puertas, que fueron recuperando un aspecto pavonado tras decapar o chorrear, a baja presión, los negros esmaltes y acabados, y aplicar después un pasivador del óxido, una crema de grafito y una cera microcristalina.

La integración cromática para matizar las grandes manchas sobre los morteros de posguerra de las bóvedas (provocadas por antiguas humedades y carbonataciones), se realizó con pigmentos minerales mediante la técnica del "tratteggio" (entramado de líneas), con mejor resultado que las veladuras por su efecto impresionista, diferenciador, sobrepuesto al fondo donde se aplica. Y en el caso de la labra escultórica se reintegraron las pequeñas lagunas $\mathrm{y}$ 

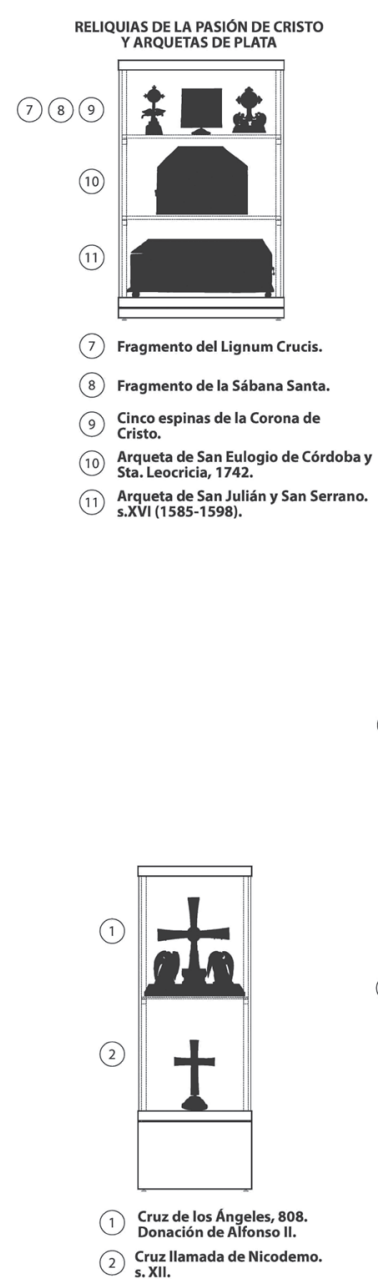
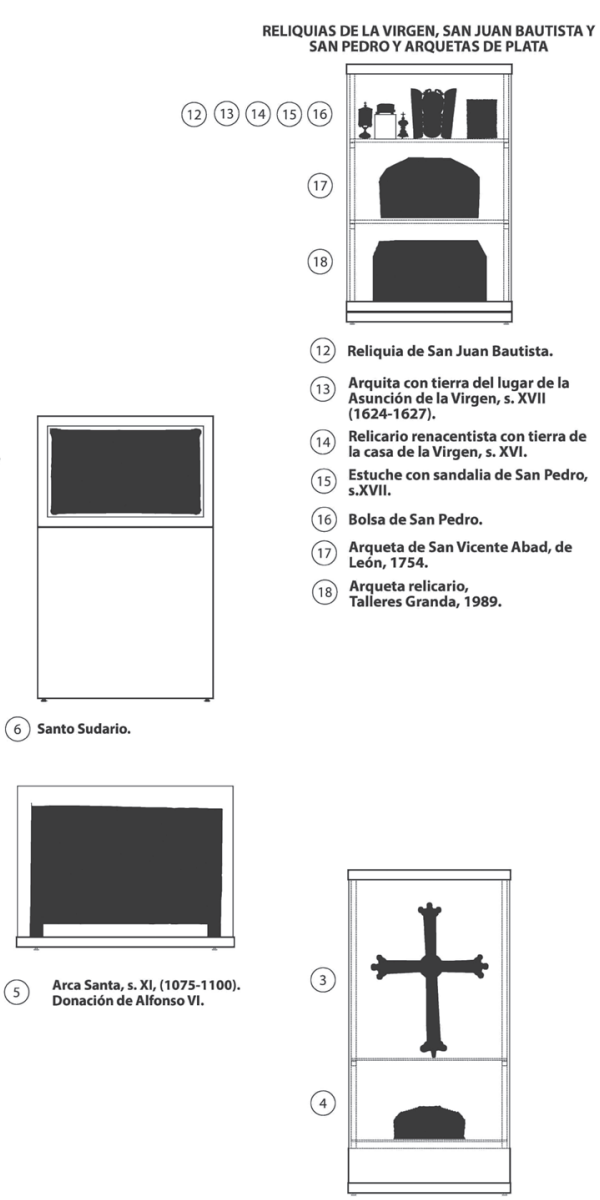

(3) Cruz de la Victoria, 908.

(4) Arqueta de las Ágatas, 910.
Donación de Fruela II.
Fig. 6. Esquema gráfico de los contenidos de las vitrinas. escamaciones que existían en su patinado utilizando veladuras de acuarela diluida.

Incluso aparecieron unos restos de policromías en la bóveda del Camarín que se asemejan a unos ropajes de posibles personajes.

El sistema de iluminación artificial fue sustituido por otro de menor consumo y más eficaz, con dos encendidos: uno general, indirecto, mediante luz reflejada sobre las bóvedas (proporcionada por tiras de led's alojadas sobre las impostas), y otro focal, directo, vinculado a las propias vitrinas y destinado a iluminar las piezas a venerar o exponer (que se activa con la presencia de los visitantes), proporcionando, así, la atmósfera precisa. Esta atmósfera es la que se corresponde con un santuario, y no con un museo, por lo que de manera consciente la iluminación directa, de acento, se ajustó de tal manera que sólo proporcionase un pequeño halo de luz. Y como complemento lumínico se dispusieron dos pequeños proyectores, con luz cruzada, para iluminar las tres cabezas del Calvario (los situamos sobre los cimacios del eje jerárquico del apostolado, los correspondientes a los Príncipes de los Apóstoles - S. Pedro y S. Pablo - y a los hijos de Zebedeo - Santiago y S. Juan).

También se ordenó la forma de exponer la orfebrería medieval, las arquetas, y las reliquias con una nueva disposición, aprobada previa $\mathrm{y}$ unánimemente por todos los canónigos del Cabildo, tras desmontar el anterior mobiliario, que empequeñecía el Santuario, con sus pétreas y pesadas bases. Estas bases se trasladaron al Seminario (las de los laterales y tras gestionar su almacenamiento junto a otros depósitos anteriores procedentes de la catedral), o al callejón del Olivo, en el Cementerio de Los Peregrinos (la base central). 


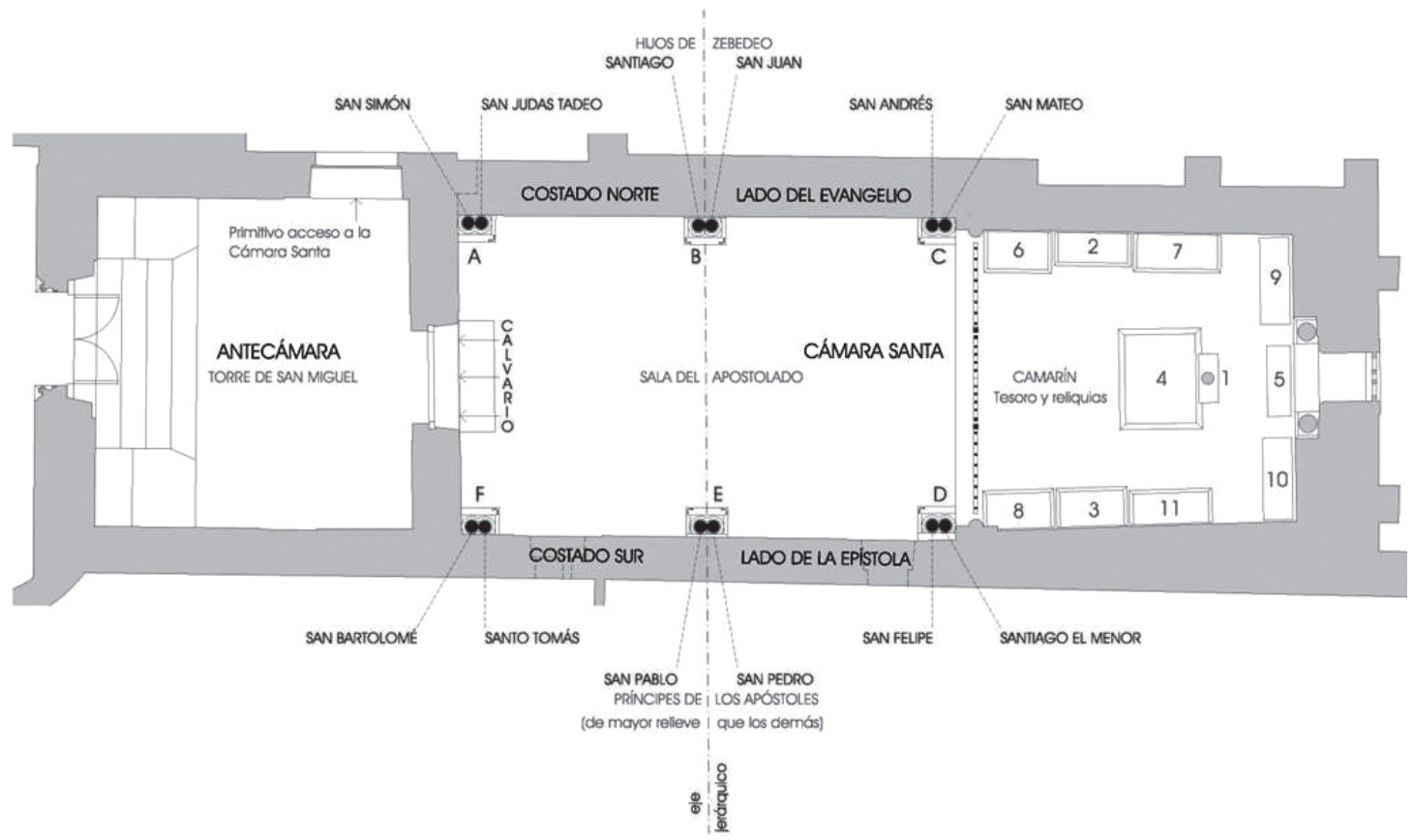

TESORO Y RELIQUIAS DE LA CÁMARA SANTA

1 Cruz de Los Angeles. S. IX (808). Donación de Alfonso II E Casto.

2 Cruz de la Victoria, s. X (908). Donación de Alfonso Ill y Scemena (Jimena).

3 Caja de las Ágatas, s. X (910). Donación de Fruela ll y Nunilo.

4 Arca Santa, s. X. Posible factura en vida de Alfonso V.

5 Santo Sudario. En un marco de madera chapeado en plata y con dos asas donado por el obispo de Plasencia, antes de Oviedo, Juan Francisco Manrique de Lara (1754-1760), en 1763.

6 Arca gótica de San Eulogio de Córdoba y Santa Lucrecia, s. XIV (1305). Donación del obispo Fernando Álvarez de las Asturias (1302-1323).

7 Arca de San Jullán y San Serrano, s. XV. Escudos de la catedral y del obispo Dlego Aponte de Quiñones (1585-1598)

8 Arca barroca de San Vicente Abad de León, s. XVIII. Rehecha en 1753 sobre la primittiva de 1268.

9 Vitrina neobarroca con relicarios: estuche de plata con la suela de la sandalia de S. Pedro; relicario con las espinas de Cristo; cajtia de coral, s. XMl; otros objetos y relliquias.

10 Vitrina neobarroca con relicarios: Cristo de Nicodemo, s. XII, con un frogmento de lignum crucls; lienzo de la Pasión de Cristo (fragmento de la Sábana Santa); Otros objetos y reliquilas.

11 Arca modema de plata, s. XX (1.989). Contiene los restos de Santos que albergaba el Arca Santa.

Fig. 7. Esquema planta y contenidos estado previo. Cuenca y Hevia

En la nueva ordenación se jerarquizó su colocación, según la importancia del objeto a venerar, mediante nuevas vitrinas, más diáfanas, conformadas con vidrios laminados de seguridad de $4+4 \mathrm{~mm}$. del tipo extraclaro (optiwhite) y con iluminación propia, supeditadas a la arquitectura interior y que posibilitan ver los reversos de las principales piezas por medio de unas láminas especulares orladas con un vinilo de transición; se recuperó el carácter mueble del Arca Santa (con sus cuatro patas a la vista, antes ocultas y mal ventiladas) que fue situada sobre la base cuadrangular descubierta del primitivo altar altomedieval; y se colocó el Santo Sudario en un estuche protector microclimático anóxico (sin oxígeno) dentro de una vitrina climatizada para mejorar sus condiciones de conservación, dotada de una iluminación inocua mediante fibra óptica, según las recomendaciones del EDICES (Equipo De Investiga- ción Centro Español de Sindonología) y de su miembro asturiano Jesús García Iglesias. Este estuche microclimático, por su peso (unos 20 Kg.), requiere la disposición de un atril para su ostensión en las fechas que tradicionalmente se muestra la reliquia, por lo que fue necesario diseñar y materializar uno para el día de Viernes Santo (lo pintamos de gris oscuro, por ser el color tanto del estuche como del peldaño del Altar Mayor donde se ubicará). Para la evacuación del agua de los equipos de deshumidificación y climatización eran necesarios sendos sumideros, que ya existían en el suelo del testero del Camarín, y que se pusieron al descubierto tras desmontar el anterior mobiliario.

En su afán investigador este equipo llevó a cabo una jornada de análisis e inspección del Santo Sudario el sábado 1 de marzo de 2014, bajo la coordinación de Felipe Montero Ortego, utilizando un potente microscopio óptico bino- 
cular Nikon SMZ-1000 (resulta sorprendente la información que han podido extraer, hasta la fecha, de esa inagotable fuente de datos que proporciona el textil bimilenario de lino, pero esa es otra historia que deberá contar el EDICES).

Los escasos elementos metálicos de las vitrinas se pintaron con un color gris neutro (RAL 7040), buscando la mayor discreción y sobriedad, pues se trataba de que tuviesen el menor protagonismo posible. Asimismo el color del tejido Baumann que forraba el interior de la vitrina del Santo Sudario también fue gris, por el mismo motivo.

La nueva disposición de las reliquias, las cruces y la orfebrería se organizó con seis vitrinas, que se fabricaron en Eslovenia, según la siguiente ordenación:

- Un eje longitudinal principal constituido por el Arca Santa y el Santo Sudario, alojado en el estuche microclimático anóxico dentro de una atmósfera ligeramente presurizada de nitrógeno o argón (foco de atracción de todo el conjunto situado en posición realzada tras el Arca Santa y alrededor del cual giran las demás vitrinas). Este estuche es similar al que se utilizó para conservar "La dama del armiño" (hacia 1490), de Leonardo da Vinci, y que también fue realizado por el mismo especialista, Guillermo Andrade.

- Un primer eje transversal - flanqueando al anterior y en posición adelantada - con dos vitrinas albergando la Cruz de Los Ángeles y la Cruz de Nicodemo (la de la izquierda), y la Cruz de la Victoria y la Caja de las Ágatas (la derecha). Su altura, igual en las dos, se ajustó para que las tapas metálicas que coronan ambas vitrinas pasasen desapercibidas desde la puerta de entrada, al quedar ocultas, visualmente, tras la barra horizontal de la verja del Camarín.

- Y en un segundo eje transversal - en posición retrasada y adosada al testero - con otras dos vitrinas, cuya altura no rebasa la línea de imposta, en las que se colocaron otras reliquias de la pasión de Cristo y dos arquetas de plata (en la situada a la izquierda), y varias reliquias de La Virgen, San Juan Bautista y San Pedro, más las otras dos arquetas de plata (en la derecha).

Esta ordenación quedó reflejada mediante unas infografías y un esquema gráfico, que se colocó sobre la verja del Camarín impreso sobre un vidrio templado, con el fin de facilitar a los visitantes y peregrinos la identificación de las 18 piezas expuestas.

Los aparejadores que intervinieron, Manuel Fernández, en la dirección de la ejecución, y David Carracedo, en la coordinación de seguridad y salud, fueron el sostén de la disciplina técnico-económica de la obra, realizada sin incidente alguno pese a las dificultades que entrañaba por el trasiego de andamios, equipos, personal laboral, investigadores, contenidos singulares, y medios de comunicación social (que pudieron comprobar, en su visita del día 20 de marzo, que el recinto de trabajo más que una obra parecía un quirófano).

El nuevo aspecto que presenta la Cámara Santa es el resultado del trabajo de un equipo técnico pluridisciplinar, del consenso logrado con los numerosos científicos e investigadores consultados, de la impulsora iniciativa de la Dirección General de Patrimonio Cultural, del apoyo del Cabildo y del Deán D. Benito Gallego (con el refrendo del Sr. Arzobispo), de la profesionalidad de la empresa restauradora (TRYCSA) y su jefe de obra (Jaime Represa), y de la pericia de los responsables del equipamiento de las nuevas vitrinas (TOP Design Europe). Por tan larga nómina de participantes, y de otras muchas personas que también colaboraron, no detallamos la relación personalizada de sus nombres y apellidos, pero sí dejamos constancia de un hecho importante: nadie, ni una sola persona escatimó esfuerzos por la responsabilidad y el privilegio de poder trabajar en la Cámara Santa de la Catedral de Oviedo. De esta manera lo que se inició como restauración fue mutando en resurrección - parafraseando al difunto deán D. Rafael Samoano con motivo de la actuación en el claustro del año 2003 - pues tal es la diferencia entre los estados inicial y final del interior de la Cámara Santa.

Pudieron complicarse las cosas por la Ley 14/2013 de Apoyo a los Emprendedores, que introduce seis modificaciones al texto refundido de contratos del sector público, al no distinguir la restauración monumental de otras obras, pues ni la clasificación empresarial que se requiere (la K-7) ni la experiencia previa en trabajos similares podían contabilizarse, en nuestro caso, como méritos o ventajas a la hora de adjudicar estos inusuales trabajos de restauración. Menos mal que los medios técnicos 

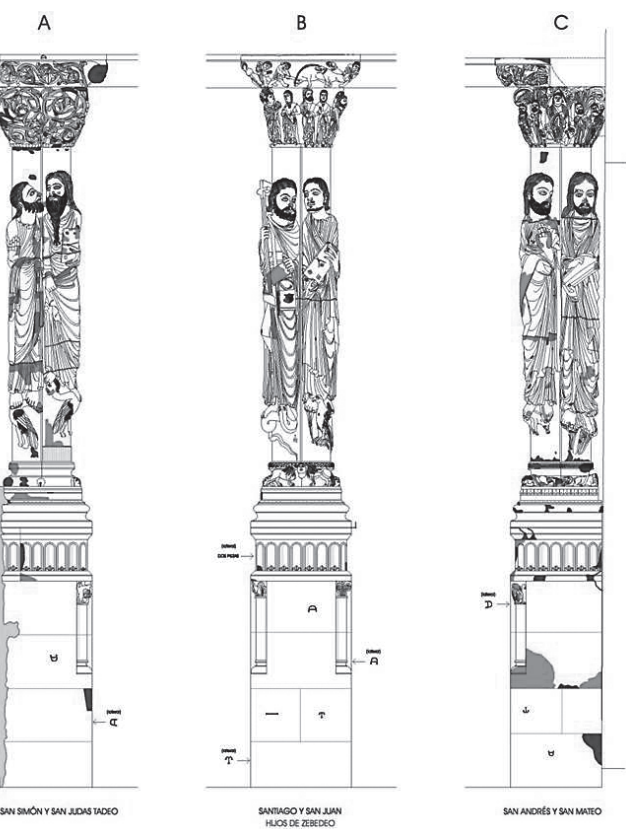

Fig. 8. Mapeo de las patologías del Apostolado. Cuenca y Hevia.

y humanos necesarios para su ejecución eran también inhabituales, lo que marcaba de hecho el perfil técnico de la empresa que se requería, y eso fue, precisamente, lo que ayudó.

Viene aquí al caso, como curiosidad y salvando las distancias (331 años), la famosa carta que el ingeniero militar francés Vauban (responsable de la construcción de fortificaciones) envió en 1683 a Louvois, Ministro de la guerra de Luis XIV: "Hay algunos trabajos en los últimos años que no han terminado y que no se terminarán, y todo eso Monseñor, por la confusión que causan las frecuentes rebajas que se hacen en sus obras, lo que no sirve más que atraer como contratistas a los miserables, pillos o ignorantes, y ahuyentar a aquéllos que son capaces de conducir a una empresa. Yo digo más, y es que ellos retrasan y encarecen considerablemente las obras porque estas rebajas $y$ economias tan buscadas son imaginarias y lo que un contratista que pierde hace lo mismo que un náufrago que se ahoga, agarrarse a todo lo que puede: y agarrarse a todo, en oficio de contratista, es no pagar a los suministradores, dar salarios bajos, tener peores obreros, enganar sobre todas las cosas y siempre pedir misericordia contra esto y aquello”.

"Y de ahi bastante, Monseñor, para hacerle ver la imperfección de esa conducta; abandónela pues, y en nombre de Dios, restablezca la
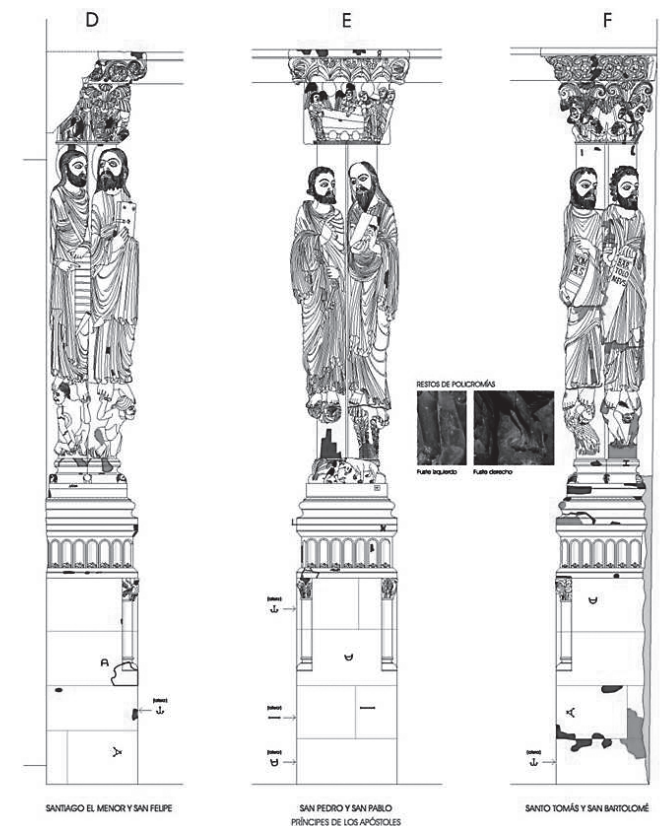

buena fe: encargar las obras a un contratista que cumpla con su deber será siempre la solución más barata que podéis encontrar".

Gracias al nuevo aspecto recuperado, a la información recabada durante el proceso restaurador, y a la mayor legibilidad conseguida, se podrán discernir, ahora, aquellos casos dudosos del repertorio iconográfico y decorativo románico, con sus detalles ornamentales, propiciándose, de esta manera, la actualización de los estudios sobre la Cámara Santa y los importantes contenidos que alberga (las reliquias de la pasión de Jesucristo y las cruces emblemáticas de Asturias, entre otras relevantes piezas). Para facilitar las futuras tareas de estudio e investigación se realizó un registro fotográfico final que completó la secuencia gráfica que teníamos: 1918 (antes de la destrucción) - 1941 (el final de la reconstrucción) - 2012 (el estado previo que encontramos) - (2014 el estado en que lo dejamos).

Y para rematar tan minuciosa intervención, aprovechando la circunstancia del traslado del Arca Santa durante los trabajos en el interior del Camarín, y tras poder observarla en detalle sobre el soporte elevado construido al efecto, se propuso, al principio de la obra, realizar un tratamiento completo de limpieza y conserva- 


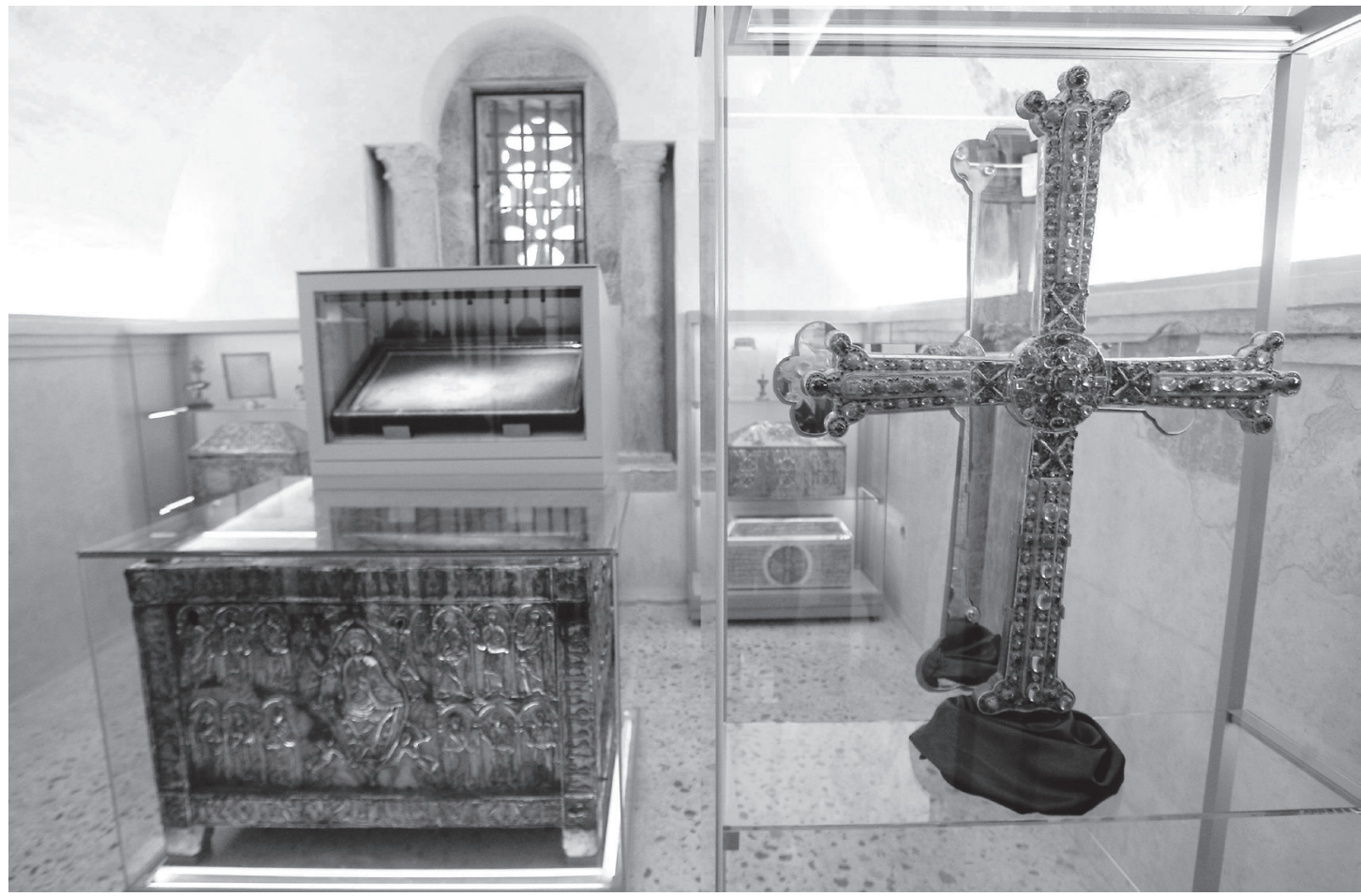

Fig. 9. Nueva ordenación expositiva. Alex Piña.

ción de los elementos ligneos y de sus chapados de plata (nielados, cincelados, repujados, grabados y dorados), tanto del repertorio iconográfico como de las inscripciones hispanovisigóticas o cúficas, a fin de re-exponerla en las mejores condiciones posibles y recuperando su carácter de arca-relicario, que se había perdido al transformarse en ara, ocultando sus cuatro patas.

Fue la ocasión para admirar esa muestra excepcional de la orfebrería medieval europea contenida en su tapa: un Calvario con cinco escenas grabadas en sus respectivas planchas de plata. En posición central Jesucristo crucificado flanqueado por la Virgen y el centurión Longinos a un lado, y por San Juan y el soldado Stefaton al otro. En la plancha de la derecha el mal ladrón: Gestas, con esbirros y demonios. A la izquierda el buen ladrón: Dimas, también con esbirros pero con ángeles, y sobre ambos, y en sus respectivas planchas, dos parejas de ángeles turiferarios (los que portan el incienso). Y para que pueda conocerse mejor esta obra de arte nos pusimos la tarea de dibujarla a tamaño natural, con todo detalle, para lo que contamos con las ortofotos de Sergio Ríos y Julio Ruiz y con la documentación que aportaron, generosamente, los profesores Lorenzo Arias y Etelvina Fernández.
Cuando se autoricen los trabajos de limpieza y conservación del Arca se hará la datación cronológica de la madera y se colocará un nuevo fondo, independiente del mueble (el anterior se perdió a causa de la voladura de 1934 conservándose un pequeño fragmento en el Museo Arqueológico), para que el Arca Santa recupere también su carácter de relicario, y se puedan alojar en su interior las diversas reliquias seleccionadas por el Cabildo. La actuación en el Arca Santa será asumida, en principio, por José Luis Alonso Benito, especialista en la restauración de orfebrería, cuya principal carta de presentación fue su trabajo en la arqueta prerrománica de Alfonso III o de San Genadio (del año 910), de la Catedral de Astorga, emparentada tipológica y cronológicamente con la Caja de las Ágatas.

En esta intervención, y como ya nos sucedió en otros casos anteriores, se ha producido también la gratificante impresión de que el edificio restaurado nos devuelve con creces los cuidados dispensados, al sorprendernos a todos por la calidad de los valores que van aflorando y que ponen de manifiesto el gran nivel artístico del Apostolado y el Calvario de la Cámara Santa, de finales del s.XII, y que constituyen una 
de las muestras escultóricas más representativas del románico español.

El último detalle fue restaurar los cuatro cuadros de los reyes de la monarquía asturiana que habían adornado antiguamente las paredes de la Cámara Santa. Su presencia en ese lugar se había constatado en el dibujo del interior que el pintor romántico Jenaro Pérez Villaamil hizo en 1846 - la imagen más antigua que conocemos y que se conserva en el Museo de Bellas Artes de Asturias - en el que se reflejan los cuatro lienzos ovales pintados por Carlos García Muñiz hacia 1815-1817: Pelayo, Fruela I, Alfonso II el Casto y Alfonso VI. La tarea fue encargada por el Cabildo a la restauradora Isabel Alonso y tras su conclusión se colgaron los cuadros en la Antecámara (en las paredes de la Torre de San Miguel).

Y como en el gran complejo catedralicio ovetense de San Salvador siempre ocurren cosas (son $7.434 \mathrm{~m}^{2}$ de espacios cerrados y cubiertos y $2.506 \mathrm{~m}^{2}$ de patios, callejones y jardines), en la madrugada del 15 de febrero una inoportuna ráfaga de viento tronchó gran parte del casi-semi-milenario olivo en el Cementerio de los Peregrinos, junto a la Cámara Santa, (providencialmente sin daño alguno que afectase a las históricas fábricas; sólo se movió el tramo inferior de un bajante de pluviales). La intervención, realizada por el Servicio de Parques y Jardines del Ayuntamiento de Oviedo, no fue de restauración sino de saneamiento y podado de tan emblemático y vetusto árbol, que con su nuevo porte, disminuido, ya no ofrece riesgo alguno (se guardó un fragmento para su datación).

Tras la restauración de la Cámara Santa se va a organizar un nuevo régimen de visitas de forma que no se formen grupos superiores a veinticinco personas en su interior (una persona por metro cuadrado y no dos como venía siendo hasta la fecha). De esta manera se pretenden atemperar los incrementos de temperatura y humedad relativa que se producian en las épocas de mayor afluencia de visitantes, a fin de mejorar las condiciones de conservación del apostolado románico y de los contenidos que alberga el recinto.

Por tal medida resulta aconsejable disponer una exposición con tres pantallas interactivas, en la antesala de acceso, sobre aquellos aspectos y detalles menos visibles de los contenidos de la Cámara Santa (la tapa del Arca Santa y sus laterales, la decoración de sus letras cúficas, los capiteles y cimacios del apostolado, los detalles de sus cabezas y las del Calvario, el Santo Sudario - con la documentación del EDICES - y las principales reliquias, etc.), lo que ayudaría a los guías cuando los grupos sean de cincuenta personas (la cabida de un autobús), al poder fraccionarlos en dos. Un equipo técnico coordinado por Julio Ruiz (ITMA) ya concluyó esa tarea haciendo las secuencias fotográficas de cada elemento, para su definición espacial mediante tecnologías 3D, empleando métodos combinados de fotografía de alta resolución, restitución fotográfica y realidad virtual (el trabajo fue financiado por el Ayuntamiento de Oviedo).

Y como recuerdo de la visita también se han maquetado diversas propuestas utilizando las imágenes recopiladas -dibujos, planos y fotos- a fin de hacer posible la renovación del material gráfico existente mediante la edición de postales, marcalibros, dípticos, trípticos y pósters (una actualización del merchandising).

En los últimos días de obra, en concreto el miércoles 2 de abril, visitaron la Cámara Santa unos representantes del Banco Europeo de Inversiones -en compañía de la Directora General de Finanzas y Hacienda Dña. Raquel Pereira Vegas, del Sr. Viceconsejero de Cultura y Deporte D. Alejandro Calvo Rodríguez y de otros técnicos de la consejería- a los efectos de comprobar la marcha de los trabajos financiados.

En la recta final de los trabajos (los días 7, 8, 9 y 10 de abril de 2014) fue necesario hacer un plan de obra de mañanas y tardes para asegurar que en la fecha prevista para la inauguración (el día 11) no faltase detalle alguno. Justamente en la víspera quedó resuelto el problema de sustentar, en vertical, la Cruz de la Victoria, y gracias a que Pedro Díaz Gómez encontró una antigua base metálica, muy adecuada, que ya había caído en el olvido. Tras su forrado se cubrió con una tela de color verde, en consonancia con el color verdoso que marca los cantos del vidrio de la vitrina, para no introducir más colores, y en aras de buscar la sobriedad que el santuario reclamaba.

El miércoles 16 de abril, haciendo de anfitriones el Sr. Arzobispo, el Sr. Vicario, y el Sr. Deán, fue la visita institucional de las autoridades del Gobierno del Principado de Asturias: su Presidente D. Javier Fernández Fernández, el 


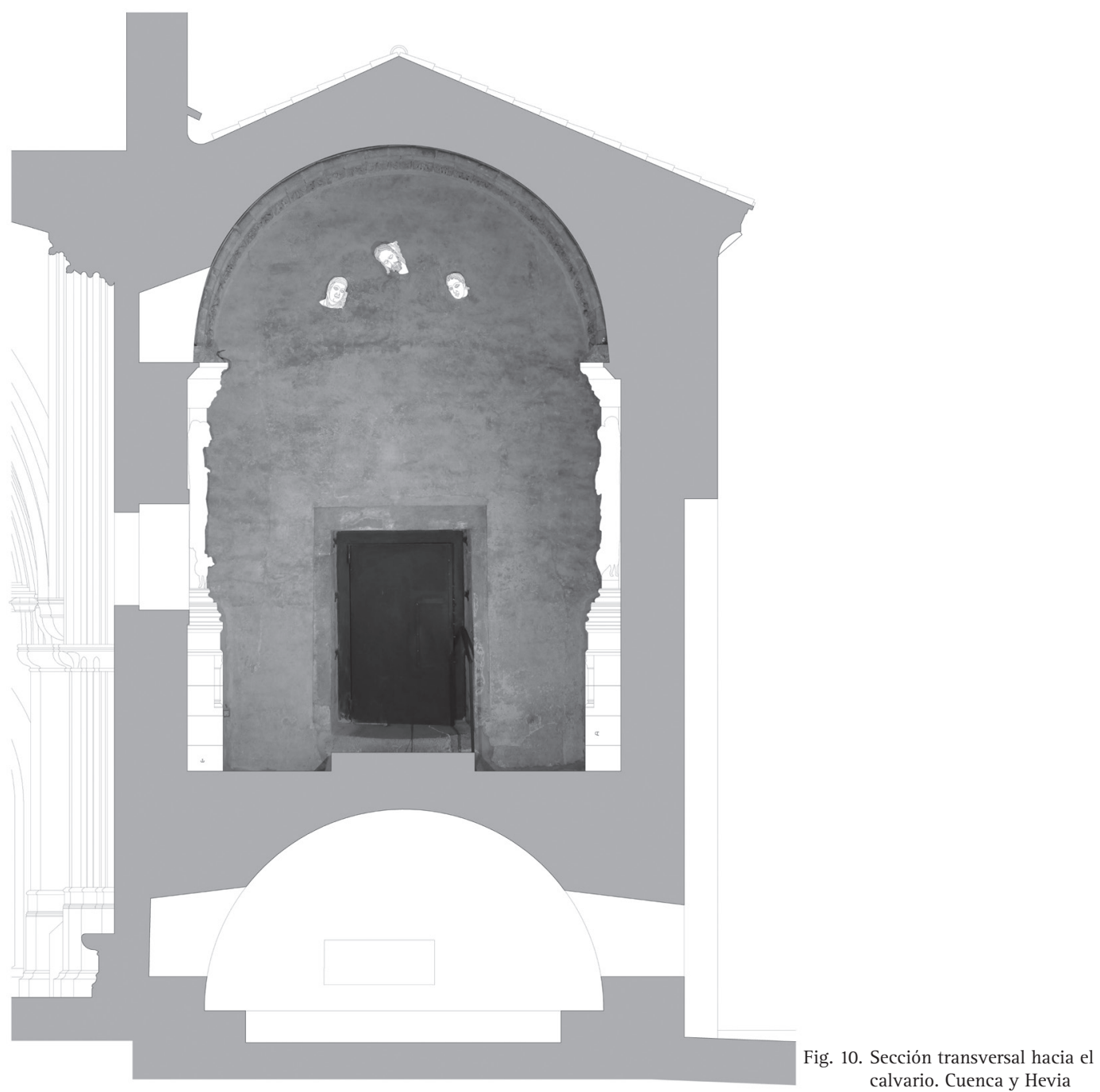

Consejero de Presidencia D. Guillermo Martínez Suárez, la Sra. Consejera de Educación, Cultura y Deporte Dña. Ana González Rodríguez, y el Sr. Director General de Patrimonio Cultural D. Adolfo Rodríguez Asensio. Y también estuvo el Sr. Alcalde de Oviedo D. Agustín Iglesias Caunedo. Durante esta visita se anunció la restauración del Arca Santa, a cargo del Principado de Asturias, lográndose así el necesario remate final que reclamaba la Cámara Santa. Para propiciar este trabajo la nueva vitrina cuenta con puerta frontal y fondo deslizable, sobre dos carriles, que permite ver la base del altar altomedieval gracias al recorte que se le ha practicado.

Finalmente sólo cabe reseñar y agradecer la conjunción de esfuerzos e iniciativas de cuantas personas y entidades han intervenido en este proceso, bien directamente - con sus manos, su técnica, y su ciencia -, bien insti- tucionalmente - financiándolo, apoyándolo y tutelándolo. Y aunque sea de forma muy simplificada hay que indicar también los criterios de intervención que, en general, fueron muy sencillos: respetar y valorar tanto las aportaciones del pasado, como las ya asumidas socialmente, mediante la eliminación de cuanto resultaba superfluo o degradante (corrigiendo deficiencias y patologías, recuperando la legibilidad escultórica perdida, mejorando la forma de exponer los contenidos y supeditando a la arquitectura interior tanto el mobiliario como las instalaciones). Y todo ello con un claro objetivo: que la Cámara Santa recupere su valor y pueda potenciarse como foco de peregrinación del mundo cristiano incardinado en el Camino de Santiago.

Por estar aún muy presente el recuerdo del expolio de las Cruces y la Caja de las Ágatas, de 1977, nos pareció que no era ésta la ocasión 
para plantear una posible sustitución de la reja del Camarín, al ser éste un santuario y no un museo.

Con esta actuación, y desde la primera intervención realizada en el año 1997, se ha alcanzado un grado de cumplimiento del Plan Director de la catedral de Oviedo superior al 85\%, logro importante conseguido gracias a la suma de numerosas voluntades durante los últimos 17 años. Este logro, en cualquier caso, es un pálido resultado frente a la ingente tarea llevada a cabo en la Cámara Santa tras su destrucción en 1934, y por tal motivo debe concluirse esta crónica con un renovado reconocimiento al equipo humano que la reconstruyó.

\section{2a INTERVENCIÓN (2013). PLAN DIRECTOR DE LA CATEDRAL DE OVIEDO.}

Obras de restauración en la Cámara Santa. Segunda Fase.

Proyecto: Mayo 2013. Consejería de Educación, Cultura y Deporte. Gobierno del Principado de Asturias.

\begin{tabular}{|c|c|}
\hline \multicolumn{2}{|c|}{ EQUIPO TÉCNICO PLURIDISCIPLINAR } \\
\hline \multirow{2}{*}{ Arquitectos } & Jorge Hevia Blanco y Cosme Cuenca Busto. \\
\hline & Autores del proyecto y directores de obra. \\
\hline Aparejador & Manuel Fernández Fernández. \\
\hline Coordinador de Seguridad y Salud & David Carracedo Carrasco. \\
\hline Arqueólogo & Sergio Ríos González. \\
\hline \multirow{4}{*}{ Restauradores } & Luis Suárez Saro \\
\hline & Pablo Klett Fernández. \\
\hline & Sara Prieto Muñiz. \\
\hline & José Prieto Nieto. \\
\hline Petrólogos & Araceli Rojo, Luis Valdeón y Félix Mateos. (GEA). \\
\hline Historiador asesor del Plan Director & Vidal de la Madrid Álvarez. \\
\hline Electricidad & Hermanos Ludeña. \\
\hline Iluminación & Victorino Viejo del Río (Metalux). \\
\hline Seguridad & Stanley Security. \\
\hline Equipamiento vitrinas & Top Design Europe (Grupo SIT). \\
\hline Estuche microclimático anóxico & Top Design Europe (según pautas del EDICES). \\
\hline Fotografías & $\begin{array}{l}\text { Julio Ruiz y Luis Rovés (ITMA), Carlos de Posada, Pedro } \\
\text { Díaz Gómez y equipo pluridisciplinar. }\end{array}$ \\
\hline Constructor & $\begin{array}{l}\text { TRYCSA. Técnicas para la Restauración y Construcciones, } \\
\text { S.A. }\end{array}$ \\
\hline Jefe de obra & Jaime Represa Bermejo, arquitecto. \\
\hline Fecha de ejecución & 25 Noviembre 2013 / 10 Abril 2014. \\
\hline Fecha de inauguración & 11 Abril 2014. \\
\hline Fecha de reposición & $\begin{array}{l}\text { Acto litúrgico celebrando la nueva reposición, con oración } \\
\text { por las reliquias, el sábado } 12 \text { de abril de } 2014 \text {. }\end{array}$ \\
\hline
\end{tabular}


